\title{
Values-led Participatory Design as a pursuit of meaningful alternatives
}

\author{
Tuck Wah Leong \\ Interaction Design and Human Practice Lab \\ Faculty of Engineering and Information \\ Technology \\ University of Technology Sydney \\ tuckwah.leong@uts.edu.au
}

\author{
Ole Sejer Iversen \\ Department of Communication and Culture \\ Aarhus University \\ Helsingforsgade 14 \\ 8200 Aarhus N, Denmark \\ oiversen@cavi.au.dk
}

\begin{abstract}
Participatory Design (PD) is inherently concerned with inquiring into and supporting human values when designing IT. We argue that a PD approach that is led by a focus upon participants' values can allow participants to discover meaningful alternatives - alternative uses and alternative conceptualizations for IT that are particularly meaningful to them. However, how PD works with values in the design process has not been made explicit. In this paper, we aim to (i) explicate this values-led PD approach, (ii) illustrate how this approach can lead to outcomes that are meaningful alternatives, and (iii) explain the nature of meaningful alternatives. We use a PD case study to illustrate how we work with participants in a values-led PD approach towards meaningful alternatives.
\end{abstract}

\section{Author Keywords}

Values, Meaningful alternatives, Participatory Design, Design

\section{ACM Classification Keywords}

H5.m. Information interfaces and presentation (e.g., HCI): Miscellaneous.

\section{INTRODUCTION}

This paper is directed at designers of interactive technologies and HCI specialists who are interested in designing for human values. It introduces a productive approach to designing technologies that support human values - a goal pursued by many others such as Halloran et al. (2009), Lloyd and McDonnell (2009), Friedman and Kahn Jr (2008) and Nathan et al, (2008, 2007). However, this approach differs from them in that it offers ways of thinking and working with values to design IT within the Participatory Design (PD) tradition. While PD has an inherent concern for human values (eg. Frauenberger et al. 2015; Greenbaum \& Loi, 2013; Vines et al. 2013;
Iversen et al. 2010; Iversen et al. 2012; Simonsen \& Robertson, 2012), how PD practitioners work with values, and what kinds of outcomes that can be gained through a values-led PD have not been made explicit. As such, this paper aims to (i) explicate this values-led PD approach, (ii) illustrate how this approach can lead to outcomes that are meaningful alternatives, and (iii) explain the nature of meaningful alternatives. We illustrate this approach by presenting and discussing a PD case study -Wizefloor- conducted in the educational setting where we worked with a range of values to pursue meaningful alternatives. In doing so, the paper contributes to offering one approach to supporting human values when designing IT.

\section{Meaningful alternatives}

Meaningful alternatives are possible outcomes of a values-led PD process used to design a digital artifact. There are two facets to these design outcomes. First: a material outcome - the (designed) product. Second: immaterial outcomes, best described as 'transformations' of the participants' ways of thinking. Thus, besides designed artefact(s), possible outcomes include the potential capacity for people to reimagine their future use of technology with respect to particular values. For Ehn, design is all about - "the dialectics of tradition and transcendence" (1988). And when we engage people in dialogue with their values during design, we are in fact supporting them to discover alternative (transcendence) outcomes or futures that are meaningful to them with respect to their current practice (tradition), i.e., their existing practice(s) within the context of what is being designed. Because of this, the designed artifact(s) are more likely to fit well with people's practices, potentially experienced as being meaningful during use, and is more likely to be embraced by those who are involved in this design process.

Both material and immaterial outcomes are meaningful to the participants because the outcomes are developed from the participants' own values during the design process and grounded upon the participants' existing practice. The outcomes are 'alternatives' because through the design process, participants come to realize alternative solutions to the range of products that conventionally exist or are commercially available. Bødker (2003) alluded to this 'alternative' when she argued that one remit of $P D$ practitioners is "not so much to build their [participants'] future technology but to help them realize 
that they have a choice". She added that it is "our duty as researchers to keep questioning what use quality may mean as the technological possibilities change, to keep exploring and offering alternatives and be critical as to how such alternatives may be used in actual work settings" (ibid). But first, we will clarify our conception of values and how we work with values in a design process.

\section{VALUES}

Values are enduring beliefs that we hold concerning desirable modes of conduct or end-state of existence in different situations, societies and cultural contexts (Rokeach, 1973; Almond \& Wilson, 1988). Desirable modes of conduct could be taking care of loved ones, or being active and healthy; while desirable end-states could be a preference for peaceful existence or democracy. Values have a transcendental quality. They guide actions, behavior, attitudes, judgments and comparisons across specific objects and situations and beyond immediate goals to more long-term goals (Almond \& Wilson, 1988; Halstead \& Taylor, 2000). Our values or value system comprise of a structure or generalized plan, within whose frame or horizon we collectively try to determine, from case to case, what is good or valuable, what is preferable and not, what we endorse or oppose, what we believe in or not. Not all judgments we make about our conduct are values. For example, a preference for coffee over tea does not indicate an expression of a value, but choosing to be a vegetarian out of a concern for animal welfare is, because it signals a desirable mode of conduct (Rokeach, 1973). In short, values become criteria or standards that guide our actions, judgments and decisions, and are fundamental to what makes us human (Rokeach, 1973; Halstead \& Taylor, 2000; Harper et al., 2008).

\section{Participatory Design and values}

Methodologically, PD conceptualizes the design process as a mutual learning process. This is accomplished through the direct involvement of end users and stakeholders through workshops, collaborative prototyping and enacted scenarios (Simonsen \& Robertson, 2012). PD also has an inherent concern for values. This design approach "makes explicit the critical, and inevitable, presence of values in the system development process" (Suchman, 1993 p.viii). That is why PD is associated with a well-developed repertoire of tools and techniques that designers can use to engage people in dialogue - to be aware of, to think and reflect about, and so on - about their values throughout the design process (McCarthy \& Wright, 2004; Halloran et al., 2009). But it is not just the participants' values that shape the design process. Besides working with participants' values, Iversen and Leong (2012) also highlight ways in which designers shape the design decisions by their own values and choices. In fact, discussing shared values between designers and participants are critical in the PD design process (Dindler \& Iversen, 2014). While the importance and role of values in PD is clear, there has not been any attempts to explicitly illustrate and discuss how designers can work with and support values during design. As Frauenberger et al. (2015) suggest, there is a need to be more explicit as to how values are treated in the design process. Thus this paper is our attempt to present one approach of how we can work with values when conducting PD. By prioritizing values and through mutual learning as well as working with values in a specific way, this approach results in outcomes that are meaningful alternatives. Below, we will discuss how we conceptualize and work with values in this approach.

\section{Conceptualizing values and working with values in Values-led PD}

How we conceptualize (and work with) values in this PD approach differs from others (e.g., Nathan, et al., 2008, 2007 and Friedman and Kahn 2008) who have written about values in HCI. Unlike Nathan et al (2008, 2007), who create values scenarios to guide designers, we work with our participants to support the emergence of relevant values and continue to develop these values throughout the process. We differ from Friedman \& Kahn (2008), who see values as a universal prescribed checklist of 'twelve values of ethical import'. We don't subscribe to a set (and fixed) list of values, nor do we see values as adhering to the pre-existing categories. Values, even when held as general orientations, are not static, but emergent. There are situations that introduce new values that may conflict with older ones and it is possible for individuals to hold contradictory values (Almond \& Wilson, 1988). Within HCI, this view aligns with how Halloran et al., (2009) conceive values. It also differs from Cockton (2004) who conceives value as 'worth'.

The way we work with values requires designers to consider not only people's current needs but also the motivations driving their needs. Since people's values do not conform to a fixed list, the designer has an a priori commitment to find ways to cultivate and support the emergence as well as the discovery of local expressions of users' values. Throughout the design process, the designer must be mindful of further expression of values and this includes dealing with any potential conflicts of values (Iversen et al., 2010).

This values-led PD approach differs from other established user-oriented design traditions such as UserCentered Design (UCD). UCD seeks to fulfil users' needs or to solve their problems by producing a solution or artefact that best fits their needs (Sanders, 2002). Thus, UCD asks how we can design better products by consulting users. Values-led PD addresses the same question but achieves this by asking how designers can create a space for co-creation and co-exploration with participants. More specifically, this approach provides scaffolds for working with values: supporting its emergence, developing it with participants, with an aim to potentially change how they think about, use and live with IT.

Briefly, this approach begins with the designer inquiring into people's values. This involves the use of various tools and techniques to facilitate and cultivate the emergence of values with participants. Then, and throughout the design process, these emergent values are developed with participants through a dialogical process. This dialogical process supports "explicit discussions of design intentions; explication of values embedded in 
design strategies and choices; shared discussions amongst participants of the values that are implicit and explicit in imagined futures and changes in practices envisioned in design projects" (Gregory, 2003). But engaging with values also means engaging with dilemmas, which arise from a conflict of values. Here, a dialogical process is found to be useful to help transcend these dilemmas. The designer can use different tools and techniques to constantly reframe the dilemma with participants, and through dialogue, allow participants to perceive the dilemma from different angles and perspectives in a hope that they may discern meaningful alternatives (Iversen et al, 2012). Dilemmas are transcended when people can discover meaningful alternatives. This act of constantly 'seeing as' (Schön, 1983) encourages creative leaps; supporting people to potentially transcend the limitations of their current dilemma (Löwgren \& Stolterman, 2004). In our approach, creative leaps can be facilitated through stimulating people's imaginings. As we will explain through the case study, the designer must ensure that this imagining always involves values at play. This dialogical process to encourage creative leaps through imagining is employed whether or not there are dilemmas to transcend during the design process. And when people can successfully locate elements in one of these imagined future scenarios to resonate with their values within their current practice, then this particular imagined future would constitute an instance of a meaningful alternative to them.

Finally, this process also involves the values that designers bring to the design process. All designers bring their own set of values, embedded in their skills and repertoire. The tools that they choose to use when working with participants are also an expression of their values. While they may work together with participants, they are still exercising (professional) design decisions (Nelson \& Stolterman, 2003). Yet, these decisions are constantly negotiated with participants through design interventions. Next we present a PD case study that illustrates how working with values and a pursuit of meaningful alternatives provides a trajectory in our design work.

\section{CASE STUDY: WIZEFLOOR}

The case we present - the Wizefloor project - was an education-based PD project that we (the designers) were commissioned to undertake between 2004-2006. We choose to use the Wizefloor (despite its 'age') as the case study because unlike most PD projects, the Wizefloor was eventually commercialized. More importantly, Wizefloor is a unique example of how outcomes from a values-led PD process can continue to have significant and enduring effects beyond its original contexts. As of 2015, the Wizefloor is marketed in more than 20 countries as a digital learning environment for school children aged between 3-12 and to children with special needs (https://www.wizefloor.com/). Wizefloor provides an alternative to more conventional digital learning tools such as laptops, tablets and interactive whiteboards. As such, this (successful) project provides a strong case to illustrate the thinking and the workings of the process when using this approach to support values during design.
In this project, we were charged with developing new ITsupported learning environment in Danish primary and lower secondary schools. Throughout this project, we conducted 10 workshops with different cohorts of participants. However, to illustrate how we worked with values, we will only discuss two of the workshops in this paper. We chose these two workshops because they best illustrate how we worked with values during the design process. In particular, we will focus on describing how we supported the emergence of values and how we facilitated the further development of these emerged values.

\section{Supporting the emergence of values}

This values-led approach begins with activities aimed at supporting the emergence of values relevant to the project. Given the nature of the project, we focused upon values related to education. To ensure that we began with a broad set of values, we involved a diverse group of participants at this stage of the process. They included members of the local municipality, an inter-disciplinary group of researchers (computer scientists, architects, educational experts, etc.) and participants from the school: teachers, administrators and students.

We conducted various design activities such as workshops and presentations. The overall aim of these activities was to encourage the articulation of emergent values about education. The activities were designed to support collective listening, talking, and discussions, i.e., learning about each other's views. For example, representatives from each group were asked to give a short talk about their view of IT-supported education. Over 300 students of the school also put together a large dossier that addressed their vision of a Classroom of the Future. Each participant was then given an opportunity to express his or her values with regards to technology, education and school (both as an institution and the physical building), i.e., what is important and deemed to be a desirable state.

For example, teachers and administrators expressed the importance of collaborative and mutual learning instead of competition. Teachers also stressed the importance of students taking responsibility for their own learning, and working within a culture of shared resources. Both teachers and designers articulated the importance of the human body during learning (kinesthetic learning). This educational value regards learning not just as a cognitive activity but also an embodied act that involves students' felt and lived experiences during learning, respecting what students bring to their learning, and how they make sense of their learning when it is mediated by technology. Students valued an open, democratic, and inclusive school environment.

From these set of values, we were inspired to explore technologies in primary classroom settings that could provide means for full-body interactions, instead of fixed technologies such as monitors and mouse (that limit the use of the human body). It should be noted that this overture towards full-body interaction at that time was uncommon for Danish primary and lower secondary schools. Serendipitously, the team of designers had also been exploring designs for kinesthetic interaction with 
technology at that time. This gave us even more impetus to explore the value of kinesthetic learning. From here onwards, this paper will limit our discussion only to two of the emergent shared values on education - kinesthetic and collaborative learning. Kinesthetic and collaborative learning are educational values, and they represent a particular desirable mode to approach learning. Pursuing these values in design means finding ways to promote bodily interaction (kinesthetic) in learning activities and to support dialogue and collaboration between learners to achieve learning objectives. This differs from the more conventional and traditional values of didactic learning where students are expected to learn in class-based environments, sitting still and passive, with the teacher being the knower and expert as well as the source of knowledge. In fact, bringing in interactive white boards, laptops and tablets most often reinforce this didactic learning mode (eg. Northcote et al, 2010). Next, we illustrate how these values were developed with the participants in the design process.

\section{Developing values: Kinesthetic \& collaborative learning}

When developing the emerged shared values with participants, a large part of the effort involves supporting participants to rethink those values. In practice, this involves finding ways for the participants to imagine how those values could be realized in new ways through the design of new information technology in a particular given context. In this instance, we used fictional spaces. Fictional space draws attention to how a design space may develop as a field of work that is distanced from established practices and invites participants to imagine new forms of practices (Dindler, 2010). We used fictional spaces to encourage imagining in our participants in order to create a sense of dislocation in how people perceive the reality of their everyday.

As we mentioned earlier, we had been engaged with designing an interactive floor - Wizefloor - that can be controlled by body movement using camera tracking (see (Grønbæk et al., 2007) for more details). While we had built the hardware and basic software of this $4 \mathrm{~m} \times 3 \mathrm{~m}$ floor by the time this project began, we did not have any applications (e.g., education software) designed for the floor. In fact, we weren't sure how the floor could be used for education purposes, e.g., how it could be used in ways that are meaningful in a school setting and how its use can support learning, etc. So, we conducted a series of workshops to develop participants' values in ways to support them to discern meaningful alternatives, i.e., new ways this interactive floor could be designed and used for learning while supporting the shared values. By the end of the project, students were able to use this floor to practice the knowledge and skills taught at school in a playful and collaborative way (figure. 1).

We will now describe two workshops that sought to stimulate participants to imagine how the interactive floor to support the values of kinesthetic and collaborative learning in school. These workshops illustrate how roleplaying and drama can work as a fictional space to support participants' imagining.
Workshop 1: Olympics 2020 in Andorra.

This three-hour workshop involved 15 participants consisting of researchers, architects, designers, teachers and pedagogical experts. Called the 'Olympics 2020 in Andorra' (OL2020), the participants (divided into four teams) were tasked with developing new events for the 2020 Olympics in Andorra (see figure 2). Sporting events were chosen to explore the values of kinesthetic because of its obvious relationships to body and movement. Participants were told that since the Olympics would be held in Andorra (a very small nation in Europe), space would be limited and thus, the events they create had to be usable on a $4 \mathrm{~m} \times 3 \mathrm{~m}$ surface.

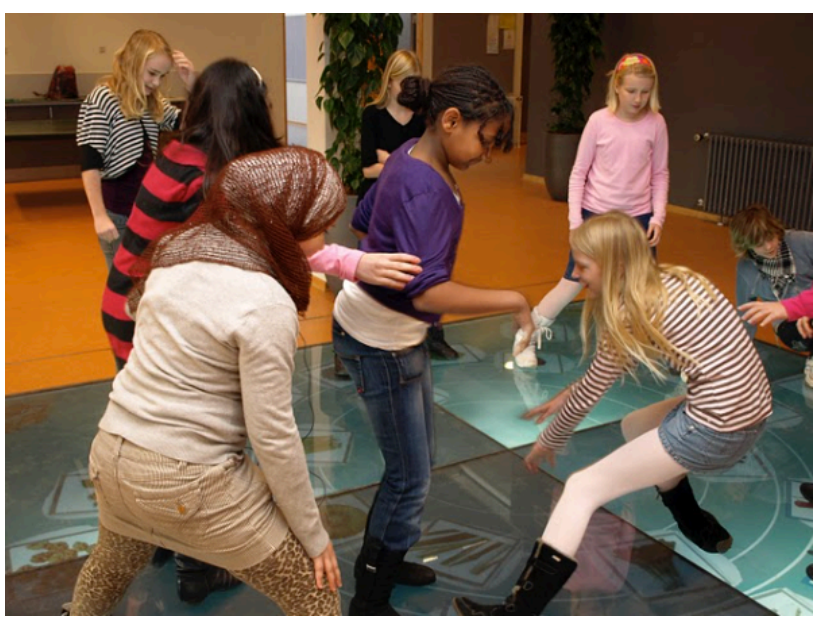

Figure 1: Wizefloor

Teams began by negotiating the premises of the task, while considering the narrative and factors that would affect their task. In doing so, they were exploring how the body could be used. For instance, one of the groups imagined that future concepts for the interactive floor could possibly extend beyond the limited twodimensional projection on the floor surface to interactions with a three-dimensional space. The provision of props also supported exploratory activities. Having props such as a variety of balls, sports equipment and so on gave participants very immediate opportunities to engage with the process. Participants would switch between playing with these artifacts, negotiate the premises of the task, and explore new possibilities. The OL2020 workshop resulted in different concept proposals that can be played on the interactive floor. All the concepts addressed the values of kinesthetic, and collaborative learning.

The OL2020 narrative served two purposes: (1) to frame the event as a physical endeavor, and (2) to promote participants' imagining. Participants had to imagine alternatives for how to use these known and familiar artifacts such as sporting equipment and props in new, unexpected and unforeseen ways for an imaginary sporting event. They did this by making sense of them relationally, i.e., by comparing them to what they already know about existing Olympic sporting events and also familiar education practices. However, at the same time, we needed to ensure that we ground this imaginary narrative within the design process. In this workshop, we used masking tape to create a constraint of a $4 \mathrm{~m} \times 3 \mathrm{~m}$ 
surface for the activity - reminding participants of the interactive floor. Thus, there was a constant interplay between the familiar and the radically unfamiliar, with participants simultaneously collaborating to explore an imaginary world with alternative ways of using their body and artifacts, while at the same time anchored to the real world of student learning using an interactive floor. Here, we must note the importance of choosing the right kinds or mix of participants when conducting activities to develop and explore particular values in specific domains. In this case, having some participants with teaching background meant that the activities played on the floor anchored the imaginings with educational concerns.

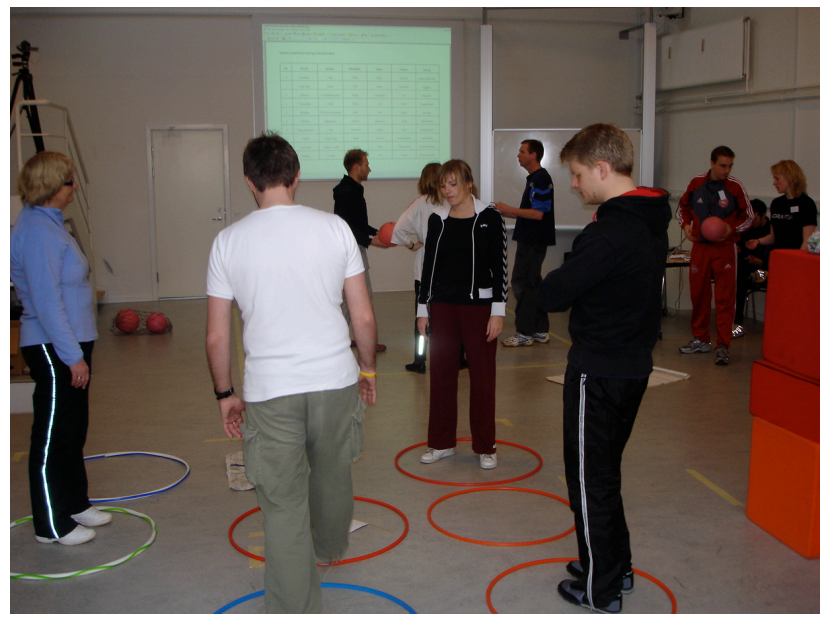

Figure 2. The Olympics 2020 (OL202) workshop

After participants have developed new events for OL2020, they were asked to work in groups to relate the concepts of their events to a matrix of different learning styles and modes of physical activity. We deliberately shifted the mode from being very exploratory to reflective. This was to ensure that the ideas were more explicitly linked to the educational theme. The mapping activity showed that the events created specifically addressed the value of collaborative forms of learning. For instance, the game should be multiplayer, competition was disallowed and the aim of the game is to foster joint endeavors to achieve collective goals. The mix of constraints and the unfamiliar (whilst still having elements of familiarity), allowed participants to imagine and create some interesting concepts that were novel and yet still grounded upon the education related values.

One of the concepts produced in this OL2020 workshop was 'Bob the Blind Builder', a geometry game in which students could get hands-on experience with learning three-dimensional geometric shapes. The idea was for a group of students to guide a blindfolded classmate to build system-generated three-dimensional figures on the interactive floor. Thus, to solve the challenge, students would need to collaborate through communication and negotiation, and in the process improve their use of geometry vocabulary. The building blocks for this game were available foam blocks of different shapes and colors appropriated by the participants. In its imagined use, these would be tracked by a (then) not-yet-existing threedimensional tracking system on the interactive floor. We can see how 'Bob the Blind Builder' has been imbued with two important values - combining kinesthetic learning (as students could physically build the figures on the floor), in a collaborative learning setup.

\section{Workshop 2: The Murder Case.}

While workshop 1 was conducted before the Wizefloor was built, a second workshop was carried out six months later with students using the Wizefloor. Although the hardware of the Wizefloor now exists, applications for it have yet to be built. Called The Murder Case, this workshop was carried out at a local primary school involving twelve students (both girls and boys) aged 1114 , their teacher (30-year-old male), and five designers. The workshop was held at the school square next to Wizefloor interactive floor. Just like the OL 2020, the workshop was designed to support participants to explore the shared values of collaboration and kinesthetic learning by encouraging students to discern/imagine prototype concepts that are meaningful to them when using this interactive floor. A detailed description of these activities is available in Brodersen et al. (2008).

The workshop was structured around a murder case narrative where students were asked to play forensic detectives tasked with solving a murder case. Each student was given a T-shirt with a New York Police Department logo to emphasize his or her role in the narrative. Role playing with the 'costume' was able to heighten the students' sense of imagining, helping to dislocate them from the school environment and the workshop. The school's square was set up as the crime scene (Figure 3 ) with the victim (a mannequin) laid next to the interactive floor with clues surrounding the body. The clues were randomly chosen by us to create an openended and highly complex point of departure for the students' investigation.

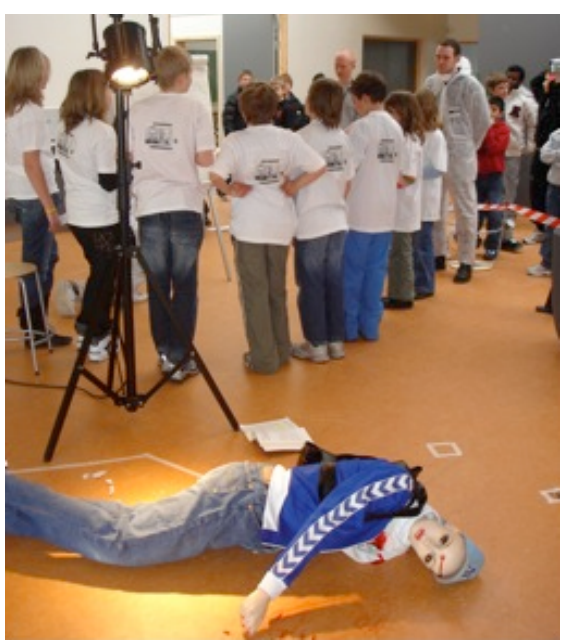

Figure 3: The Murder Case workshop

Time and place were elements used to create a sense of dislocation from participants' reality and encourage imagining. Students were told that the murder is committed in 2020, but the time of the investigation is in 2006. In other words, the students (and teacher) were encouraged to investigate a murder that had yet to be committed. Besides having to use their imagination to 
solve the murder case, they also had to deal with contradictions and unfamiliar concepts relating to their understanding of time and place. The interactive floor (Figure 1) was the wild card in solving the murder case. Participants were told that they had to use interactive floor whenever they needed assistance such as analyzing forensic evidence, modeling the crime scene or visualizing certain aspects of the crime. Since we had not implemented any functionality onto the floor, the participants had to imagine how the interactive floor might work to provide the support they needed.

A member of the design team acted as the floor technician. He discussed how the floor works with the participants and was there to provide them with answers to their requests regarding the interactive floor. Another member of the design team acted as a reporter, who could ask the 'crime investigators' about their work and what they were thinking during the murder investigation. This provided some documentation of participants' actions. Videotaped activities on the interactive floor provided further documentation.

Amongst the clues we left, one pointed to the victim's website (which we had been set up in advance). We also left footprints - indicating where the murderer had left the building and a range of strange artifacts. Students turned to the interactive floor for assistance in order to figure out these clues. While students required assistance from their teacher at the beginning of the workshop - due to the fact that many elements in the setup were too open and unfamiliar - they soon began to embrace the openendedness of the situation. Once they accepted the fact that action in this setting required them to make assumptions and to produce creative solutions, the students' imagination grew as the workshop progressed. Soon, students were turning to the interactive floor for a number of tasks and creative solutions, generating ideas that were more brazen and yet, relatively refined.

One group of girls used the floor as an over-sized digital version of the Brio ${ }^{\circledR}$ 'Labyrinth Wooden Maze Game'. They used their entire bodies as weights to control an imaginary ball on the floor. Their game design was motivated by the occupation of the deceased who, according to them had been a brilliant game designer. A group of boys believed that the killer had left some footprints on the interactive floor. They were convinced that using some imagined tools for measuring distance and angles could help explain exactly what happened at the time of the murder. This conceptualization of an application that could measure distance between points and angles was further discussed in subsequent cocreation workshops. As a result, this idea was eventually incorporated into an application designed to be used on the Wizefloor.

We specifically embedded the values of kinesthetic and collaborative learning into the Murder Case workshop set-up following the findings from the OL2020 workshops. Thus, how students chose to conduct their murder investigations demonstrated the different ways the students imagined and appropriated the values of kinesthetic and collaborative learning in this scenario. Just like the OL2020 workshop, the Murder Case workshop was an attempt to stimulate participants' imagining of values and their perception of technologyuse through creating distance in time and space. This allowed students to make creative leaps in their imaginings, enabling them to pursue new applications for the interactive floor.

\section{Grounding of values}

Grounding of values would be the final phase of how we work with values in this values-led PD. While values can be developed by encouraging participants' imagining - to reconceptualize those values - designers must also ensure that these reconceptualized values are grounded within the design outcomes (Iversen et al., 2012)

Looking back, we facilitated the grounding of values in different ways. First of all, we ensured that teachers were involved in the process. Involving teachers allowed them to see how the values of kinesthetic learning in collaborative settings could be applied practically in the classroom setting to contribute to actual learning and be manageable in their everyday teaching. Being a part of the negotiation gave them ownership and led to a commitment to the reconceptualized values. Secondly, even though we, the designers, framed the two workshops with a high level of imaginative freedom, students were still encouraged to use subject specific knowledge to solve their imagined tasks. Doing so helped ground the outcome, and to ensure its relevance within their education practice. In addition, we needed to consider ways that could support the implementation of the design into the actual real-world setting. Doing so could ensure a greater commitment by the participants to use the new designs.

Next, we will draw upon various facets of these two workshops and discuss how meaningful alternatives came about through our working with values in this approach.

\section{MEANINGFUL ALTERNATIVES \& VALUES-LED PD}

So far, we have presented some workshops that highlight how we used a particular values-led PD approach that is grounded upon participants' values in the co-design of IT. While the outcome can be an object (e.g., the Wizefloor), a software application or architecture, this approach can also create opportunities for participants to imagine new ways of using IT and new ways of conceptualizing their future relationships with IT.

In the case study presented, the outcome of the design process was the Wizefloor and a set of education applications that could be used on the Wizefloor to teach/learn mathematics and languages. However, there were other outcomes. The participants we worked with started out with a vision of the future classroom whereby each student would have access to high-speed internetconnected PCs at the start of the design process. However, by the end of this process, we found that the participants were able to envision an alternative future. For example, teachers perceived IT in a different way by the end of the process. Instead of seeing IT as a laptop or tablet, they could now see how it could be an interactive floor that supports learning and used to support shared values, whilst motivating and engaging students holistically in their pedagogical development. Our descriptions of the case highlight how meaningful alternatives can be both material and immaterial. It is 
material because the education applications produced (imbued with the particular values emerged during the design process) presented a material alternative to currently available off-the-shelf IT or conventional solutions. The education applications for the interactive floor introduced different ways whereby a kinesthetic approach to collaborative learning can occur beyond the traditional classroom settings.

Meaningful alternatives can be immaterial because people's perception and understanding (of their values, the problem, their situation, their practice, solution, etc.) could be 'negotiated' during this design process. People could end up with a different perspective of technology, finding alternate ways of thinking about technology and how it could be used within their everyday lives and their own practices. In our case study, teachers were able to rethink how kinesthetic learning could be integrated in education. Most participants could also see how technology could be experienced as being tangible, pervasive and ubiquitous instead of automatically conceiving input technology as solely dependent on mouse and keyboard. In general, our participants' perceptions about technology were also transformed from seeing it as something that they had no influence over, to something that could be designed, and shaped to fulfill their visions and values. In fact, through this project, the participants' re-conceptualization of technology has led them to further imagine new visions of IT-supported technologies for school environments. This (immaterial) re-conceptualization was found to extend beyond those directly involved in the process. During/throughout the project, various educators, researchers and politicians examined the interactive floor to see how IT-supported kinesthetic interactions could be introduced into educational setting. As a result, this project became one of the touchstone projects for new trajectories into IT-supported education in Denmark.

Next, we will provide designers with three general considerations that can guide them when using this values-led approach to conduct design inquires. These considerations could also support the shared pursuit of meaningful alternatives.

\section{Facilitating dialogue about values}

Dialogue is already considered an important element in PD (Jones et al., 2007). In this values-led design approach facilitating dialogue, especially about values, is a central element. In particular, we find Bohm's conception of dialogue very useful. For Bohm, a person in dialogue "may prefer a certain position but does not hold to it nonnegotiably". It is through this view that dialogue could give rise to something creative (Nichol, 2003). So, a core task for designers in this values-led approach is to facilitate and orchestrate this dialogue throughout the design process, i.e., from the emergence of values through to the grounding of values.

For example, in our case study, this values-led approach did not begin with any pre-defined values but instead, the designers must work closely with participants to allow for shared values to emerge through dialogue. Designers as partners-in-dialogue were careful not to enforce their design agenda. For example, the OL2020 workshop was designed with a challenge that required everyone to collaborate in order to arrive at a 'solution'. Individuals were encouraged to bring their specific skillset to meet this challenge. Architects brought their sense of space and what they saw to be an interesting learning space, while teachers contributed with their knowledge of education and understanding of how students learn. The designers brought insights of novel technologies as well as their ability to facilitate dialogue through design processes. In addition, the students' sensemaking during the Murder Case workshop also saw them participating in a collective sensemaking of this make-believe world through dialogue. Here, dialogue was also used to support and maintain each other's imagining in this make-believe world. We must note that successful facilitation of real dialogue - to bring different perspectives to some agreement - requires immense skills and a 'talent' that needs to be nurtured (Dindler \& Iversen, 2014).

\section{Creating a frame for collaborative imagining of shared values}

As illustrated in our case study, how designers frame the participants' imagining was central in supporting the pursuit of meaningful alternatives. Finding ways to stimulate imaginings whereby shared values are played out in alternative scenarios is one useful approach. The activities on the interactive floor spurred imagining through the use of Fictional Inquiry (Dindler \& Iversen, 2007). Fictional Inquiry is one of the many PD techniques that can be used to stage these kinds of imaginative activity. In the Murder Case, playing detective to solve the crime in the year 2020 forged a distance between the design space and the students' own world. As a result, this fictional design situation encouraged reflections whereby the students could reconsider their own familiar practice from a distance. Freed from constraints of the year 2006, and encouraged to act-out in this make-believe world, students' act of relational and dialogical sensemaking processes led them to respond to this future by drawing imaginatively from the familiar and from what they know, and in the process invented new practices and new technologies. Different artifacts can also be recruited to further spur imagination. In the case study, designers used various props, the set up of the space, the floor, and also orchestration of activities in various role-playing scenarios. These served as a shared fictional space that mediated participants' imagining both individually and collectively.

The use of fictional spaces (e.g., OL2020 and Murder Case) in our case study required and supported participants to act out in a fictional role within a new scenario. This allowed participants to draw from the felt and lived aspects of their lives, such as anger, curiosity, frustration, as well as their desires and hopes in relation to the values in focus. This ensured that the everyday aspects of being human would be taken into consideration in the final design of the education applications. And because the design process is grounded in participants' felt and lived experiences, the alternative solution that emerged became meaningful to them. This points to the strength of this values-led approach in general, where the felt and lived experiences of people are addressed in 
their totality. This approach aligns with McCarthy \& Wright's call to support people's dialogical imagination (2004 p.188); investing people with the potential to reexamine their own values and assumptions through dialogue and in the process, discern alternatives that are meaningful to their practice.

\section{Ensuring relevance to the design project's aim}

Ensuring relevance to the design project's aim is common to all design activities. However, how this is accomplished in this values-led approach is different. While activities to stimulate imaginings can help support participants to pursue alternatives that are meaningful to them, it is important to find ways to ground the imaginative activities so that the outcomes meet the project's aim. Designers of course bring their professional knowledge and commitments to the project. This ensures that they take the responsibility in producing outcomes that are relevant to the project. However, as the case study illustrates, designers must also ensure that the right participants are involved. It is only through the involvement of teachers, students and school administrators in the design process, that broader commitment for the project grew. Considerations about involving the right people will also help ensure that the project (and its outcomes) gain greater legitimacy and support in the long run.

\section{CONCLUSION}

This paper explicitly describes and discusses one approach whereby designers can engage with human values when using PD to design IT. In particular, it describes how this values-led approach can help realize meaningful alternatives as possible outcomes of the design process. Meaningful alternatives are realized when we support people to imagine their future use of technology in relation to particular values. To bring about this imagining, the designer can use a range of fictional spaces consisting of particular tools, props, and techniques, as well as orchestration of the design process. We found that different artifacts can be used to help shape their imagining. The use of different artifacts can also help free people from their pre-conceived ideas about the domain, potential design solutions, and so on, allowing the potential for creative leaps. While imagining may invite people into a make-believe world where they are free to envision alternative outcomes for technology, they are never entirely decoupled from reality. This is because, designers find ways to tether people's imagining to their shared values and current practices with regards to the aim of the project. In doing so, this process can derive an IT that is likely to be meaningful to people and their practices. At the same time, people who have participated in the design process would emerge with a different conceptualization of technology and more empowered in terms of how they relate to technology. By supporting people to place one foot in the world of imagined possibilities and the other in their shared values, this particular design process mediates and fosters (in the individual, as well as collectively), a continuous dialogue and sensemaking of shared values related to the domain of interest and technology. In addition, this process also supports people to envision alternative futures whereby these values could materialize. Since people's sensemaking of these envisioned futures are always dialogical and relational, this approach ensures that such alternatives are potentially meaningful to those involved. Furthermore, this process uncovers people's felt and lived notions of using technology in this envisioned future. This ensures that the design outcome is also supportive of the fuller human experience.

Of course we do not claim that this values-led PD is the only viable (or best) approach for working with human values in design. For example, Wright \& McCarthy (2010) discuss a range of approaches within the humanist design agenda that strive towards including human values in the design process. Furthermore, design cases vary from one to another an inevitable nature of design inquiries. However, we have provided some general considerations for designers to engage with this approach. A challenge with the approach we present in this paper is that it can come across as being a black art (Wolf et al., 2006). This is because pursuing meaningful alternatives through design involves a high degree of tacit design judgment and sensitivity towards values from designers - stuff that is difficult to formulate and rarely discussed explicitly. Skills that are necessary throughout the design process include orchestrating and facilitating workshops. Another challenge lies with developing better understandings of how, and to what extent, the designer's values influence the design process. Future research efforts to address these challenges, as well as efforts from designers to better document their processes and reflections could enable more fruitful and productive design inquiries to support the pursuit of meaningful alternatives. As seen in the case study, this values-led approach is often best used in open-ended, exploratory design projects.

Finally, we are cognizant of the fact that PD also comes with its theoretical traditions and inevitably developed a set of jargons that may not be familiar to all designers. So the basic motivation in presenting this perspective to the design community is not only to introduce this values-led approach to designers but more importantly to foster links, fuel dialogue and even spur partnerships between HCI researchers, designers and PD practitioners.

\section{ACKNOWLEDGMENTS}

This work was conducted by Center for Interactivespaces at Aarhus University. We acknowledge the work of Kaspar Rosengren Nielsen, Karen Johanne Kortbek, Kaj Grønbæk og Louise Aagaard in the Wizefloor project. Moreover, we are thankful to the teachers and students of Møllevangskolen and especially Gitte Molbæk for their work during the project development. 


\section{REFERENCES}

Almond, B., \& Wilson, B. (Eds.). (1988). Values: A symposium. Atlantic Highlands, NJ: Humanities Press International Inc.

Bødker, S. (2003). A for Alternatives. Scandinavian Journal of Information Systems, 15(1), 87-89.

Brodersen, C., Dindler, C., \& Iversen, O. S. (2008). Staging imaginative places for participatory prototyping. CoDesign, 4(1).

Cockton, G. (2004). From quality in use to value in the world In CHI '04 extended abstracts on Human factors in computing systems (pp. 1287-1290). Vienna, Austria ACM Press.

Dindler, C. (2010): The construction of fictional space in participatory design practice, Journal of CoDesign, Taylor \& Francis, Vol. 6(3).

Dindler, C., \& Iversen, O. S. (2007). Fictional Inquirydesign collaboration in a shared narrative space. $\mathrm{Co}$ Design, 3(4), 213-234.

Dindler, C. and Iversen, O.S. 2014. Relational expertise in participatory design. In Proceedings of the 13th Participatory Design Conference: Research Papers Volume 1 (PDC '14), Vol. 1. ACM, New York, NY, USA, 41-50.

Ehn, P. (1988). Work-oriented design of computer artifacts. Stockholm, Sweden: Arbeitslivscentrum.

Frauenberger, C., Fitzpatrick, G., Good, J. \& Iversen, O.S. 2015. In In pursuit of rigour and accountability in participatory design, Journal of human-computer Studies, Vol 74, p.93-106.

Friedman, B., \& Kahn Jr, P. (2008). Human values, ethics and design. In A. Sears \& J. Jacko (Eds.), The humancomputer interaction handbook: fundamentals, evolving technologies (pp. 1241-1266). New York: Lawrence Erlbaum Associates.

Gregory, J. (2003). Scandinavian approaches to Participatory Design. International Journal of Engineering Education, 19(1), 62-74.

Greenbaum, J. \& Loi, D. (2012). Participation, the camel and the elephant of design: an introduction, Journal of CoDesign, Vol. 8, Issue 2-3, Taylor Fancis Online, p.81-84.

Grønbæk, K., Iversen, O. S., Kortbek, K. J., Nielsen, K. R., \& Aagaard, L. (2007). Interactive floor support for kinesthetic interaction in children learning environments. In Proc of INTERACT. Rio de Janeiro, Brazil, 361-375: Springer Verlag.

Halloran, J., Hornecker, E., \& Stringer, M. (2009). The value of values: Resourcing co-design of ubiquitous computing. Co-Design, 4(5), 245-273.

Halstead, J.M. \& Taylor, M.J. (2000) Learning and Teaching about values: a review of recent research, Cambridge Journal of Education, 30(2), 169-202.

Harper, R., Rodden, T., Rogers, Y., \& Sellen, A. (Eds.). (2008). Being human: Human-computer interaction in the year 2020. Cambridge, UK: Microsoft Research Ltd.

Iversen, O. S., Halskov, K., \& Leong, T. W. (2010). Rekindling values in participatory design, Proc of PDC (pp. 91-100). Sydney, Australia.

Iversen, O.S. and Leong, T.W. (2012). Values-led participatory design: mediating the emergence of values. In Proceedings of the 7th Nordic Conference on Human-Computer Interaction: Making Sense Through Design (NordiCHI '12). ACM, New York, NY, USA, 468-477.

Iversen, O.S., Halskov, K., \& Leong, T.W. (2012) Values-led Participatory Design, Journal of CoDesign 8 (2-3), 87-103

Jones, P., Christakis, A., \& Flanagan, T. (2007). Dialogic design for the intelligent enterprise: Collaborative strategy, process, and action. In International Symposium of the International Council on Systems Engineering. San Diego, USA, 1-16.

Lloyd, P., \& McDonnell, J. (2009). Editorial: Special issue on values in the design process. Design Studies, $30(2)$.

Löwgren, J., \& Stolterman, E. (2004). Thoughtful interaction design: A design perspective on Information Technology. Cambridge, Massachusetts: MIT Press.

McCarthy, J., \& Wright, P. (2004). Technology as experience. Cambridge, USA: MIT Press.

Nathan, L.P., Klasnja, P.V., \& Friedman, B (2007). Value scenarios: a technique for envisioning systemic effects of new technologies. In Proceedings of the SIGCHI Conference on Human Factors in Computing Systems (CHI '07). ACM, New York, NY, USA, 25852590.

Nathan, L.P., Friedman, B., Klasnja, P.V., Kane, S.K. \& Miller, J.K. (2008). In Proceedings of the 7th ACM conference on Designing Interactive Systems. ACM, New York, NY, USA, 1-10.

Nelson, H. G., \& Stolterman, E. (2003). The design way. Engelwood Cliffs, NJ, USA: Educational Technology Publications Inc.

Nichol, L. (Ed.). (2003). The essential David Bohm. London: Routledge.

Northcote, M., Mildenhall, P., Marshall, L., \& Swan, P. (2010). Interactive whiteboards: Interactive or just whiteboards?. Australasian Journal of Educational Technology, 26(4).

Rokeach, M. (1973). The nature of human values. New York: Free Press.

Sanders, E. B.-N. (2002). From user-centered to participatory design approaches. In J. Frascara (Ed.), Design and the Social Sciences: Making connections (pp. 1-8). New York: Taylor \& Francis Books Ltd.

Schön, D. A. (1983). The reflective practitioner. New York: Basic Books. 
Simonsen, J. \& Robertson, T. (2012). Routledge International handbook of Participatory Design, Routledge.

Suchman, L. (1993). Foreward. In D. Schuler \& A. Namioka (Eds.), Participatory design: Principles and practices (pp. vii-ix). Hillsdale, USA: Lawrence Erlbaum Associates Inc.

Vines, J. Clarke, R., Wright, P., McCarthy, J., and Olivier, P. 2013. Configuring participation: on how we involve people in design. In Proceedings of the SIGCHI Conference on Human Factors in Computing
Systems (CHI '13). ACM, New York, NY, USA, 429438.

Wolf, T. V., Rode, J. A., Sussman, J., \& Kellogg, W. A. (2006). Dispelling design as the 'black art' of CHI. In Proc of CHI, 521-530: ACM Press.

Wright, P., \& McCarthy, J. (2010). Experience-centered design: Designers, users, and communities in dialogue. Synthesis Lectures on Human-Centered Informatics, 3(1), 1-123. 